\title{
USO DE COPRODUTOS DE FRUTAS TROPICAIS NA ALIMENTAÇÃO DE OVINOS NO SEMIÁRIDO DO BRASIL
}

\author{
USE OF BY-PRODUCTS OF TROPICAL FRUITS FOR FEEDING SHEEP \\ IN THE BRAZIL SEMIARID
}

\author{
Barreto, H.F.M. ${ }^{1 *}$; Lima, P.O. ${ }^{\text {A }}$; Souza, C.M.S. ${ }^{2 A}$; Moura, A.A.C. ${ }^{1 B} ;$ Alencar, R.D. ${ }^{2 B}$ \\ e Chagas, F.P.T. ${ }^{2 C}$
}

\begin{abstract}
'Departamento de Ciências Animais. Universidade Federal Rural do Semiárido. Mossoró, RN. Brasil. *felipe.barreto@ifrn.edu.br; Apattlima@ufersa.edu.br; Bandrezzabarreto@ufersa.edu.br

${ }^{2}$ Instituto Federal de Educação Ciência e Tecnologia. Rio Grande do Norte. Câmpus Apodi. Apodi, RN. Brasil. Acicilia.silva@ifrn.edu.br; Brenato.alencar@ifrn.edu.br; Cfelipe.pontes@ifrn.edu.br
\end{abstract}

\section{Palavras Chave adicionais}

Abacaxi. Caju. Goiaba. Melão. Mamão. Maracujá.

\section{RESUMO}

Os resíduos agroindustriais, coprodutos, podem servir para amenizar a falta de alimento para ovinos na região Nordeste e somam mais de 290 milhões de toneladas, representando perda de biomassa e de nutrientes, além de ser potencialmente poluidor de solos e corpos hídricos. O Brasil é o terceiro maior país produtor de frutas do mundo e o primeiro na produção de frutas tropicais, com $47 \%$ das frutas consumidas in natura e $57 \%$ processadas, cujo resíduo pode chegar a $50 \%$ da biomassa original. A região Nordeste apresenta condições favoráveis para a fruticultura, possuindo mais de 30 pólos de produção que juntos produziram 11297984 toneladas de frutas, o que corresponde a mais de $55 \%$ da produção das principais frutas tropicais do território brasileiro, com potencial de geração de 5787884 toneladas de coprodutos. As frutas estudadas foram o abacaxi, melão, caju, goiaba, mamão e maracujá que, de maneira geral representam fontes alimentares para os ovinos, apesar de terem restrições em proporção da dieta e que são diferentes para cada fruta. $O$ processo de agroindustrialização de frutas no Brasil, devido aos mercados mais exigentes, tende a gerar coprodutos com menos variação na sua composição química, o que é benéfico ao setor

\section{AdDitiOnAL KEYWORDS}

Pineapple. Cashew. Guava. Melon. Papaya. Passion fruit.

pecuário devido à qualidade do coproduto gerado.

\section{SUMMARY}

The agro-industrial residues, co-products, can serve to mitigate the lack of food for sheep in the Northeast and total more than 290 million tonnes, representing loss of biomass and nutrients, besides being potentially polluting soil and water bodies. Brazil is the third largest producer of fruits in the world and the first in the production of tropical fruit, with $47 \%$ of fruit consumed fresh and $57 \%$ processed waste which can reach 50 $\%$ of the original biomass. The Northeast region has favorable conditions for fruit growing, having more than 30 production centers that together produced 11297984 tonnes of fruit, which represents over $55 \%$ of the production of the main tropical fruit of the Brazilian territory, with the potential of generating 5787884 tons of byproducts. The fruits were studied pineapple, melon, cashew, guava, papaya and passion fruit that generally represent food sources for sheep, despite restrictions on the proportion of the diet and are different for each fruit. The process of agro-industrialization of fruit in Brazil, due to the most demanding markets, tends to generate byproducts with less variation in their chemical 
composition, which is beneficial to the livestock sector due to the quality of the byproduct generated.

\section{INTRODUÇÃO}

A ovinocultura brasileira é uma das mais importantes atividades econômicas (Silva et al., 2010) e sociais desenvolvidas, notadamente na região semiárida do Nordeste. Segundo o IBGE (2013a), das 17668063 cabeças de ovinos existentes no Brasil, o nordeste abriga 10112726 cabeças, ou seja, detém quase $63 \%$ do efetivo nacional. Apesar desse quantitativo, os índices produtivos ainda estão muito baixos para uma atividade que precisa ser competitiva. Dentre as deficiências encontradas nos sistemas de produção nordestinos, que levam a uma baixa produtividade, Costa et al. (2008) e Silva et al. (2010) apontam a predominância do sistema extensivo e Nunes et al. (2007) destaca ainda a redução na quantidade e na qualidade da pastagem no período seco, a degradação das pastagens e a não separação das crias do rebanho.

A dependência que os sistemas extensivos têm da pastagem nativa, que é conhecida como caatinga, talvez seja o fator mais preocupante, afirmam Silva et al. (2010). Isso porque a região Nordeste apresenta como característica duas estações climáticas bem definidas, sendo uma chuvosa e uma seca, favorecendo a concentração da produção de forragem em apenas quatro a cinco meses do ano. Em algumas regiões a área disponível de pastagem tem diminuído e o efetivo do rebanho aumentado, levando a uma maior pressão de pastejo e exigindo melhores práticas de manejo (François, 2009).

Sá et al. (2008) esclarecem que a adubação do solo, o descanso de pastagens, o uso de alimentação suplementar e a utilização de forrageiras conservadas são as técnicas que podem equilibrar a variação anual da disponibilidade de pasto e as exigências nutricionais dos animais. $\mathrm{O}$ uso da alimentação suplementar pode promover a redução dos fatores nutricionais e, consequentemente, elevar os índices produtivos dos rebanhos nordestinos, porém, é visto a consideração dos custos destes suplementos.

Na região Nordeste do Brasil a produção de grãos é baixa, todavia, o uso de subprodutos da agroindústria, segundo Geron et al. (2012), constitui uma importante fonte alternativa de nutrientes para os rebanhos, com custos geralmente menores que os suplementos convencionais, além de promover a redução da contaminação ambiental. Desta forma, a presente revisão bibliográfica visa caracterizar e relatar a importância dos coprodutos oriundos dos processos agroindustriais inseridos no semiárido brasileiro que podem ser incluídos na alimentação de ovinos.

\section{OPOTENCIAL DOS COPRODUTOS AGROINDUSTRIAISNA ALIMENTAÇÃODEOVINOS}

Os resíduos agroindustriais referem-se aos subprodutos, denominados atualmente de coprodutos, que são os derivados do processamento dos produtos principais da indústria. De acordo com Ben Salem (2010), os coprodutos apresentam menos fibras, são mais concentrados e, muitas vezes, apresentam melhores níveis de nutrientes, quando comparados com resíduos de culturas agrícolas. Atualmente, a maioria dos coprodutos utilizados é oriunda do processamento da indústria têxtil e alimentícia e, a partir do desenvolvimento de combustíveis oriundos de fontes renováveis, da indústria de biocombustíveis.

Apesar do índice de crescimento da agroindústria brasileira ter apresentado queda de $1,6 \%$ no acumulado no ano de 2012 (IBGE, 2013b), um estudo elaborado por Schneider et al. (2012) apontou uma geração de resíduo agroindustrial, proveniente das principais culturas brasileiras, de mais de 290 milhões de toneladas. Esses resíduos muitas vezes não são aproveitados 
e podem representar perda de biomassa e de nutrientes, além de ser potencialmente poluidor de solos e corpos hídricos, devido à lixiviação de compostos pela disposição inadequada, gerando risco de saúde pública.

Grande parte dos coprodutos podem ser utilizados na alimentação de ovinos, sendo mais acessíveis que os alimentos convencionais (Carvalho et al., 2012), contudo, podem apresentar efeitos prejudiciais aos animais e, portanto, precisam ser melhor estudados.

\section{COPRODUTOSDO PROCESSAMENTODE FRUTAS TROPICAIS}

O Brasil produziu em 2010 mais de 42 milhões de toneladas de frutas, somando as produções das vinte principais frutas, mantendo o Brasil entre os três maiores países produtor de frutas do mundo, sendo o primeiro na produção de frutas tropicais (Kist et al., 2012). De acordo com os dados apresentados por Buenoe Baccarin (2012), desse total da produção brasileira, $47 \%$ são consumidas in natura e $53 \%$ são processadas, cujo resíduo pode chegar a 50 $\%$ da biomassa original (Sousa e Correia, 2010).

A região Nordeste é uma das regiões mais produtoras e exportadoras de frutas do Brasil, contando com mais de 30 pólos de desenvolvimento agrícola em áreas irrigadas, segundo Naumov (2009). Esse destaque está associado à prevalência do clima seco da região, que torna o ambiente menos propício às doenças; a irrigação localizada para superar as limitações climáticas e ao uso de tecnologias que permitem maiores níveis de produção.

Como resultado desse potencial, tem-se o surgimento de inúmeras agroindústrias de processamento de frutos relatado por vários autores (Lousada Júnior et al., 2005, 2006; Nunes et al., 2007; Pereira et al., 2009; Nogueira et al., 2010), principalmente para agregar valor aos frutos tropicais oriundos da alta demanda produtiva (tabela I).

Ao se analisar a tabela I, observa-se que no Nordeste foram colhidos 1928034 hectares (ha) cultivados com frutas tropicais, o que representa mais de $74 \%$ da área colhida no Brasil, onde foram colhidas 11297984 toneladas, o que corresponde a mais de $55 \%$ da produção das principais frutas tropicais do território brasileiro. Observa-se que o melão (Cucumis melo L.), cacau (Theobroma cacao L.), caju (castanha e pedúnculo) (Anacardium occidentale), coco da baía (Cocos nucifera L.) e maracujá (Passiflora sp.) representam mais de $70 \%$ da área colhida no Brasil, quando se avalia cada cultura isoladamente. Com relação à produção dessas frutas, percebe-se o domínio do Nordeste em relação às outras regiões do país, principalmente paras as culturas do caju (Anacardium occidentale), melão (Cucumis melo L.), maracujá (Passiflora sp.), manga (Mangifera indica L.) e coco da baía (Cocos nucifera L.).

Levando-se em consideração o dado apresentado por Sousa e Correia (2010), que sugerem que o resíduo gerado no processamento representa $50 \%$ da matéria original, tem-se no Nordeste um resíduo estimado em cerca de 5648992 t, apenas levando em consideração as onze culturas de maior relevância apresentadas na tabela I.

\section{Coproduto do abacaxi (Ananas COMOSUSL. MERRIL)}

O Ananas comosus L. Merril é uma planta tropical originária da América Latina e o seu cultivo no Brasil, em 2012, segundo o Levantamento Sistemático da Produção Agrícola (IBGE, 2013b) atingiu a marca de 1652119 unidades do fruto produzidas, provenientes da colheita de 60653 ha. A região Nordeste do Brasil é a maior produtora com uma produção de 615272 frutos e os três maiores produtores nacionais da fruta são os Estados do Pará, Paraíba e Minas Gerais com produções de 317 127; 294640 e 
Tabela I. Área colhida, produção e representatividade de algumas frutas tropicais cultivadas no Nordeste do Brasil em 2011. (Area harvested, production, and relative importance of some tropical fruits grown in Northeast Brazil in 2011).

\begin{tabular}{lcccccr}
\hline & \multicolumn{3}{c}{ Área colhida (ha) } & \multicolumn{4}{c}{ Produção (t) } \\
Fruta & Brasil & Nordeste & $\%{ }^{1}$ & Brasil & Nordeste & $\%^{1}$ \\
\hline Abacaxi & 62,481 & 22,909 & $36,7 \%$ & 1576,972 & 610,826 & $38,7 \%$ \\
melão & 19,695 & 16,766 & $85,1 \%$ & 499,330 & 468,436 & $93,8 \%$ \\
Banana & 503,354 & 212,722 & $42,3 \%$ & 7329,471 & 2862,505 & $39,1 \%$ \\
Cacau & 680,484 & 533,315 & $78,4 \%$ & 248,524 & 156,289 & $62,9 \%$ \\
Castanha de caju & $764,472^{3}$ & $760,137^{3}$ & $99,4 \%$ & 230,785 & 227,191 & $98,4 \%$ \\
Pedúnculo do caju & & & & 2077,065 & 2044,719 & $98,4 \%$ \\
Coco da Baía & 270,541 & 219,471 & $81,1 \%$ & 1962,434 & 1373,598 & $70,0 \%$ \\
goiaba & 15,917 & 7,431 & $46,7 \%$ & 342,528 & 151,903 & $44,3 \%$ \\
mamão & 35,531 & 22,230 & $62,6 \%$ & 1854,343 & 1174,510 & $63,3 \%$ \\
Manga & 76,383 & 51,712 & $67,7 \%$ & 1249,521 & 877,715 & $70,2 \%$ \\
maracujá & 61,631 & 46,153 & $74,9 \%$ & 923,035 & 671,421 & $72,7 \%$ \\
Melancia & 97,718 & 35,188 & $36,0 \%$ & 2198,624 & 678,871 & $30,9 \%$ \\
Total Geral & 2588,207 & 1928,034 & $74,5 \%$ & 20492,632 & 11297,984 & $55,1 \%$ \\
\hline
\end{tabular}

Fonte: Adaptado de IBGE (2011).

${ }^{1}$ Percentagem da produção nordestina em relação à produção nacional. ${ }^{2}$ Dado estimado com base na produção de castanha de caju, que segundo Machado et al. (2012) representa apenas $10 \%$ do fruto. ${ }^{3}$ Foi considerada, na contabilidade da área, como sendo uma área comum para obtenção dos dois produtos.

250576 frutos, respectivamente.

Além da comercialização da fruta in natura, o abacaxi serve de matéria-prima para muitos produtos alimentícios, destacando-se o seu uso no processamento para obtenção da polpa de fruta (Costa et al., 2007), gerando resíduos como casca, coroa, brotos, anexos da fruta moídos, miolos e polpa (Ferreira et al., 2009) que podem ser utilizados na alimentação animal devido, principalmente a sua palatabilidade e níveis significativos de carboidratos solúveis, cerca de $9,2 \%$ na matéria seca (MS).

Jerônimo (2012), ao realizar um estudo sobre a gestão dos resíduos nas agroindústrias, apontou uma produção residual de $37,5 \%$ para o beneficiamento do abacaxi para produção de polpa, enquanto Pereira et al. (2009) ao realizarem um apanhado bibliográfico encontraram valores que variaram de 30 a $50 \%$.
A composição química do coproduto do abacaxi, a exemplo das demais frutas, varia de acordo com as proporções das partes da fruta presente nele e é influenciada pela qualidade do fruto, forma de processamento e de armazenamento. Na tabela II encontrase a composição química do coproduto do abacaxi a partir de diversos estudos.

Ao avaliarem níveis de inclusões de 0 , 11,16 e $27 \%$ de coproduto do abacaxi desidratado (CAD) na dieta de ovinos machos inteiros, Rogério et al. (2007), observaram consumos de matéria seca (CMS) que variaram de 4,02 a 5,28\% do peso vivo (PV), cuja variação, está associada aos constituintes da parede celular (hemicelulose e lignina), sendo, portanto, recomendado o nível de inclusão de até 16 $\%$ de CAD, tendo em vista que maiores proporções comprometerão o consumo de nutrientes. Contudo, quando o CAD é 
Tabela II. Matéria seca (MS), proteína bruta $(P B)$, lignina (Lig), extrato etéreo (EE), fibra em detergente neutro (FDN), fibra em detergente ácido (FDA) e matéria mineral (MM) do coproduto do abacaxi de acordo com alguns autores. (Dry matter (MS), crude protein (PB), total carbohydrate (CT), lignin (Lig), ether extract (EE), neutral detergent fiber (FDN), acid detergent fiber (FDA) and mineral matter (MM) of the coproduct pineapple according to some authors).

\begin{tabular}{lcccccccc}
\hline \multirow{2}{*}{ Autor } & \multicolumn{1}{c}{ Composição (\% da MS) } \\
& MS & PB & CT & Lig & EE & FDN & FDA & MM \\
\hline Lousada Jr. et al. (2006) & 84,67 & 8,35 & 83,68 & 5,29 & - & 71,39 & 30,74 & 6,78 \\
Ferreira et al. (2007) & 87,40 & 9,20 & - & 10,50 & - & 60,70 & 24,10 & - \\
Rogério et al. (2007) & 88,51 & 9,25 & 80,21 & 10,05 & 1,34 & 66,14 & 34,41 & 9,2 \\
Pereira et al. (2010) & 97,62 & 7,84 & 80,82 & 9,84 & 0,60 & 60,30 & 32,86 & 10,70 \\
Azevedo et al. (2011) & $13,91^{1}$ & 7,09 & - & 3,71 & 0,78 & - & 34,11 & 4,48 \\
\hline
\end{tabular}

${ }^{1}$ Matéria seca obtida pela análise do coproduto in natura.

incluído como aditivo no processo de ensilagem permite melhores níveis de consumo, em virtude da melhoria da qualidade nutricional como observado por Neiva et al. (2009).

Ferreira et al. (2007) ao analisarem o efeito da inclusão de CAD na ensilagem do capim-elefante, observaram que a adição permitiu um incremento de MS da silagem, sendo acrescido 0,59\% de MS para cada 1 $\%$ de CAD, o que melhorou a eficiência do processo fermentativo. Além disso, foi observado efeito linear positivo para a qualidade da silagem, proteína bruta (PB) e MS, até o nível máximo de inclusão estudado que foi de $14 \%$ da matéria natural. Efeito similar foi percebido por Neiva et al. (2009) quando comparou a silagem de capim-elefante exclusiva com a silagem de capimelefante aditivada com 10,5\% de CAD. Pompeu et al. (2006) também percebeu aumentos lineares de MS, bem como diminuição dos teores de fibra em detergente neutro (FDN) e de fibra em detergente ácido (FDA), com a inclusão de $0 ; 5 ; 10 ; 15$ e $20 \%$ do CAD na ensilagem de capimelefante, contudo, não percebeu incremento nos teores de PB.

Com relação ao desempenho dos ovinos alimentados com coproduto do abacaxi
Neiva et al. (2009) encontraram superioridade no ganho de peso de ovinos, quando comparou a silagem de capim-elefante exclusiva $\left(93,4 \mathrm{~g}_{\text {animal }}{ }^{-1} \mathrm{dia}^{-1}\right)$ com a silagem de capim-elefante adicionada com $10,5 \%$ de CAD $\left(164,8 \mathrm{~g}\right.$ animal $\left.^{-1} \mathrm{dia}^{-1}\right)$, sendo os dois tratamentos suplementados com concentrado $(23,5 \%$ PB e $79 \%$ NDT). Santana et al. (2004) ao avaliarem os rendimentos e cortes especiais da carcaça de ovinos alimentados com silagem contendo o mesmo nível de inclusão estudado por Neiva et al. (2009) não encontraram diferenças estatísticas, mas apontam maiores rendimentos tanto verdadeiros como comerciais da carcaça de cordeiros Santa Inês.

\section{Coproduto do melão (Cucumis melo L.)}

O meloeiro (Cucumis melo L. )é originário da África Central, de onde se difundiu para o Oriente Médio e Ásia Central, sendo cultivado no território brasileiro desde a década de 60. O cultivo desta fruta não é expressivo quando analisamos a sua área colhida (19 695 ha) e comparamos com as das principais frutas, pois supera apenas a área colhida da goiaba (Psidium guajava) que foi de 15917 ha, em 2011 (tabela I). Em 
contrapartida, o melão é a fruta com o maior volume de exportação, alcançando em 2011, 169575 t e cifras da ordem de 128 milhões de dólares (Kist et al., 2012).

Essa cultura torna-se importante no cenário da utilização de coprodutos agroindustriais no semiárido pelo fato de 85 $\%$ da sua área plantada está localizada na região Nordeste do Brasil, representando uma produção de mais de $468000 \mathrm{t}$ de frutos. Figura-se entre os Estados mais produtores o Rio Grande do Norte (258938 t), Ceará (143 $466 \mathrm{t}$ ) e a Bahia (41 892 t) de acordo com os dados apresentados pelo IBGE (2011).

De toda a produção da fruta $70 \%$ são comercializados no mercado nacional, regional e local, dentre as quais $20 \%$ são destinadas a exportação e $10 \%$ é considerado refugo (Costa et al., 2011b; Lima et al., 2012). O refugo é caracterizado como sendo a fruta que apresenta defeitos na sua aparência ou tamanho inadequado e, por isso, não pode ser comercializado como fruta fresca. Logicamente que nem toda a produção de melão de refugo está disponível à alimentação animal, sendo parte delas utilizadas pela indústria de sucos, cuja produção de coprodutos corresponde de 45 a $66 \%$ da matéria-prima original (Pereira et al., 2009).

A variação na composição do coproduto do melão se dá devido ao tipo de coproduto (Refugo ou resíduo da produção de sucos), à variedade do melão produzido, irrigação, adubação e exigência do mercado consumidor. Alguns trabalhos realizados têm demonstrado que os coprodutos do melão apresentam boa composição química (tabela III), corroborando com a afirmativa do seu potencial para uso na alimentação animal.

Estudos realizados por Lima et al. (2012), utilizando o coproduto do melão (frutorefugo) em substituição (0; 30; 60 e $100 \%)$ do milho na dieta de ovinos da raça Morada Nova, observaram que houve efeito quadrático, com valores máximos no nível de inclusão de $60 \%$ de melão-refugo, para o consumo de MS (910 g animal dia ${ }^{-1}$ e 3,5\% do PV) e de nutrientes (158 g PB; 30 g EE; $416 \mathrm{~g}$ FDN, $785 \mathrm{~g}$ NDT; $684 \mathrm{~g}$ carboidratos totais (CT) e $267 \mathrm{~g}$ carboidrato não-fibrosos (CNF)/animal/dia) para os machos não-castrados. Os autores afirmam que essa depressão do consumo ocorreu devido ao aumento do percentual de FDN e da lignina, em virtude da substituição do milho.

Foi observado por Lima et al. (2012) efeito linear positivo, em função da substituição de até $100 \%$ do milho pelo melão-refugo na dieta do ovinos, para a digestibilidade aparente de vários nutrientes, atingindo valores de 94,65\%;84,48 $\% ; 65,0 \%$ e $96,0 \%$ para PB, EE, FDN e Carboidratos não fibrosos (CNF), respectivamente. Contudo, o efeito inverso ocorreu com a digestibilidade aparente da matéria seca que foi reduzido de 80,11 para 49,66\%, entre os níveis de 0 e $100 \%$ de substituição, proporcionando menores ganhos de peso, à medida que se incluiu o melão-refugo. Lousada Júnior et al. (2006), entretanto, ao estudar o coproduto do melão encontrou uma digestibilidade in vitro de 55,26\%.

Avaliando o ganho de peso de borregos não-castrados, submetidos a quatro regime de manejo alimentar, Araújo et al. (2009) encontraram resultados promissores e divergente do apontado por Lima et al. (2012). Eles observaram que a substituição de $50 \%$ da matéria seca do concentrado fornecido com base em $2 \%$ do PV dia ${ }^{-1}$, por coproduto de melão, não afetou o desempenho dos ovinos em estudo.

A substituição do milho pelo coproduto do melão não afetou significativamente ( $p>0,05)$ as características quantitativas da carcaça, como mostram os resultados observados em Costa et al. (2011a), sendo, portanto, indicada a substituição de até 100 $\%$ do milho pelo coproduto do melão sem prejuízos à avaliação da carcaça.

Essa mesma indicação é recomendada por Costa et al. (2011b), devido aos seus ensaios mostrarem que não houve diferenças significativas $(\mathrm{p}<0,05)$ na composição centesimal do músculo semmimembranosus 
Tabela III. Matéria seca (MS), proteína bruta $(P B)$, lignina (Lig), extrato etéreo (EE), fibra em detergente neutro (FDN), fibra em detergente ácido (FDA) e matéria mineral (MM) do coproduto do melão de acordo com alguns autores. (Dry matter (MS), crude protein (PB), total carbohydrate (CT), lignin (Lig), ether extract (EE), neutral detergent fiber (FDN), acid detergent fiber (FDA) and mineral matter (MM) of the coproduct melon according to some authors).

\begin{tabular}{lccccccccc}
\hline \multirow{2}{*}{ Autor } & \multicolumn{7}{c}{ Composição (\% da MS) } \\
& MS & PB & CT & Lig & EE & FDN & FDA & MM \\
\hline Lousada Júnior et al. (2006) & $84,56^{3}$ & 17,33 & 64,84 & 16,61 & 3,26 & 59,10 & 49,18 & 14,57 \\
Pereira et al. (2009) & $13,50^{2}$ & 17,60 & 64,80 & 13,10 & - & 59,20 & 47,80 & 11,30 \\
Pereira et al. (2010) & $97,53^{3}$ & 8,75 & - & 33,46 & 0,80 & 73,00 & - & 6,85 \\
Lima et al. (2011) & $7,05^{2}$ & 11,90 & 76,52 & - & 1,09 & 23,02 & - & - \\
Lima et al. (2012) & $7,28^{2}$ & 11,58 & 69,94 & 5,86 & 7,62 & 20,58 & 16,68 & 9,30 \\
\hline
\end{tabular}

${ }^{1}$ Dados de composição do coproduto da agroindústria. ${ }^{2}$ Matéria seca obtida pela análise do coproduto in natura. ${ }^{3}$ Matéria seca obtida a partir do coproduto desidratado.

(umidade, matéria mineral, proteína e lipídio), nem nos atributos sensoriais da carne, como o odor $(4,75 \pm 1,40)$, a maciez $(2,29 \pm 1,64)$, a suculência $(4,85 \pm 1,52)$ e o sabor $(4,78 \pm 1,41)$. Esses resultados mostram que a substituição de até $100 \%$ do milho pelo coproduto do melão, não afeta a qualidade nutricional da carne, nem compromete a sua aceitação pelos apreciadores.

\section{Coproduto do caju (Anacardium OCCIDENTALE)}

O cajueiro (Anacardium occidentale) é originário do continente americano e ocupa lugar de destaque entre as plantas frutíferas tropicais. O Brasil apresenta uma área plantada de 764475 ha, sendo quase toda a área colhida (764 472 ha) para o processamento da castanha, que rende 230785 t (IBGE, 2011), das quais $26301 \mathrm{t}$ foram comercializadas para exportação, gerando uma receita de mais de 226 milhões de dólares em 2011 (Brasil, 2013). Os dados oficiais só compilam as informações produtivas da cajucultura para a produção de castanha, portanto, para o levantamento da produção de pedúnculo foi considerada a estimativa de que a castanha compreende apenas $10 \%$ do peso do caju (Lopes et al., 2011; Machado et al.,
2012), o que levou a uma produção nacional estimada em 2077065 t em 2011.

A produção, tanto da castanha quanto do pedúnculo, está concentrada na região Nordeste, cuja produção representa 98,4\% da produção nacional (IBGE, 2011). Analisando o cenário brasileiro, percebe-se que oito, dos onze Estados produtores, encontra-se inseridos na região Nordeste, que tem como principais produtores o Ceará $(48,4 \%)$, Rio Grande do Norte $(23,5 \%)$ e Piauí $(19,8 \%)$.

Os produtos do caju compreendem a amêndoa da castanha-de-caju (ACC) e o Líquido da castanha de caju (LCC), oriundos do processamento da castanha; doces, sucos e cajuína, provenientes do processamento do pedúnculo (pseudofruto) do caju e a própria venda do caju in natura.

O resíduo gerado pelo processamento do pedúnculo do caju na indústria gera, de acordo com Jerônimo (2012), 32 \% de coproduto. Contudo, a discussão a cerca dos coprodutos do caju será com ênfase ao coproduto da comercialização da castanha que é o pedúnculo in natura sem castanha, cuja produção se concentra no período de estiagem e, conforme afirma Souza Filho et al. (2010), mais de $90 \%$ é desperdiçada e que 
apresenta composição variável em função da forma de produção, método de secagem e variedade (tabela IV).

Avaliando silagens de capim-elefante com níveis de inclusão de bagaço de pedúnculo do caju desidratado (BPCD) $(0 ; 4 ; 8 ; 12$ e $16 \%$ ) na alimentação de ovinos, Teles et al. (2010) observaram que os níveis de inclusão não afetaram o consumo de MS e foram considerados relativamente bons $\left(46,38 \mathrm{~g} \mathrm{~kg}^{-1} \mathrm{PV}^{0,75}\right)$ para silagem de capim elefante. Analisando o consumo de nutrientes, os mesmos autores relataram um maior consumo de $\mathrm{PB}\left(3,96 \mathrm{~g} \mathrm{~kg}^{-1} \mathrm{PV}^{0,75}\right)$, EE $\left(2,20 \mathrm{~g} \mathrm{~kg}^{-1} \mathrm{PV}^{0,75}\right)$ e $\mathrm{CNF}\left(7,79 \mathrm{~g} \mathrm{~kg}^{-1} \mathrm{PV}^{0,75}\right)$ no maior nível de inclusão; não foram observadas alterações no consumo de FDN $\left(30,21 \pm 5,55 \mathrm{~g} \mathrm{~kg}^{-1} \mathrm{PV}^{0,75}\right)$ eFDA $(18,74 \pm 3,54 \mathrm{~g}$ $\left.\mathrm{kg}^{-1} \mathrm{PV}^{0,75}\right)$, contudo, a digestibilidade da $\mathrm{PB}$ foi baixa $(42,35 \pm 6,71 \%)$ e pode estar associada à alta concentrações de nitrogênio insolúvel em detergente ácido (NIDA).

Ao estudar níveis crescentes de polpa de caju desidratada $(0 ; 10 ; 20 ; 30$ e $40 \%)$ em dietas para ovinos em confinamento, compostas por milho, farelo de soja e feno de tifton, Dantas Filho et al. (2007) observaram melhores consumos de MS (1,54 $\mathrm{kg}$ animal $\left.{ }^{-1} \mathrm{dia}^{-1} \mathrm{e} 4,48 \% \mathrm{PV}\right)$ ao introduzir 10 $\%$ da polpa de caju na dieta, possivelmente pelos menores teores de FDN (42,9\%), FDA $(20,49 \%)$ e lignina $(5,88 \%)$ registrados. Neiva et al. (2009) ao submeterem ovinos a rações a base de silagem de capim elefante exclusiva ou contendo subprodutos da produção de sucos do caju, observou maiores consumos de MS $\left(960 \mathrm{~g}\right.$ animal $^{-1}$ $\left.\mathrm{dia}^{-1}\right)$, PB (138,6g animal $\left.{ }^{-1} \mathrm{dia}^{-1}\right)$ e FDN (464,6 $\mathrm{g} \mathrm{animal}^{-1} \mathrm{dia}^{-1}$ ), quando houve inclusão do coproduto e, consequentemente, proporcionou melhores ganhos em peso $\left(154,4 \mathrm{~g}\right.$ animal $\left.^{-1} \mathrm{dia}^{-1}\right)$.

Estudando o desempenho produtivo de ovinos sem padrão racial definido (SPRD) alimentados com silagens de capim elefante, contendo ou não a adição de BPCD, associado com concentrado fornecido na proporção de $1,5 \%$ do $\mathrm{PV}$, Teixeira et al. (2003) observaram que o ganho de peso foi maior quando o volumoso continha o BPCD (110g animal ${ }^{-1}$ dia $\left.^{-1}\right)$, em relação ao volumoso composto apenas por silagem (66 $\mathrm{g}_{\text {animal }}{ }^{-1}$ $\left.\operatorname{dia}^{-1}\right)$.

Ao avaliarem o desempenho e as características de carcaça em ovinos, em que a dieta consistia em ração concentrada fornecida com base em $2 \%$ do PV e volumoso composto por silagem de sorgo (Sorghum bicolor) ou BPCD, à vontade, Silva et al. (2011) perceberam que não houve diferença significativa $(p>0,05)$ para o ganho de peso

Tabela IV. Matéria seca (MS), proteína bruta (PB), lignina (Lig), extrato etéreo (EE), fibra em detergente neutro (FDN), fibra em detergente ácido (FDA) e matéria mineral (MM) do coproduto do caju de acordo com alguns autores. (Dry matter (MS), crude protein (PB), total carbohydrate (CT), lignin (Lig), ether extract (EE), neutral detergent fiber (FDN), acid detergent fiber (FDA) and mineral matter (MM) of the coproduct cashew according to some authors).

\begin{tabular}{lcccccccc}
\hline & & \multicolumn{7}{c}{ Composição (\% da MS) } \\
Autor & MS & PB & CT & Lig & EE & FDN & FDA & MM \\
\hline Leite et al. (2013) & $88,91^{1}$ & 16,10 & 75,75 & 21,19 & 4,18 & 65,85 & 40,50 & 3,97 \\
Ferreira et al. (2004) & $25,40^{2}$ & 14,20 & 77,20 & 22,50 & 4,10 & 65,50 & 47,00 & - \\
Silva et al. (2011) & $90,29^{1}$ & 14,95 & - & - & 6,64 & 81,78 & 33,07 & 4,45 \\
\hline
\end{tabular}

${ }^{1}$ Matéria seca obtida pela análise do coproduto desidratado. ${ }^{2}$ Matéria seca obtida pela análise do coproduto in natura. 
e para as medidas da carcaça in vivo, contudo, observaram que o grupo alimentado com BPCD, em relação ao grupo que consumia silagem de sorgo obtiveram melhor conversão alimentar $(8,08 \pm 0,32 v s$ $15,62 \pm 0,75 ; \mathrm{p}<0,05)$ e rendimento de carcaça $(48,24 \% \pm 0,73$ vs $44,05 \% \pm 1,33 ; \mathrm{p}<0,05)$.

\section{Coprodutoda goiaba (Psidiumguajava)}

A goiabaeira (Psidium guajava) é originária da América Tropical e, no Brasil, apresentou uma pequena área plantada (15 956 ha) e uma produção de 342528 t, em 2011 (IBGE 2011). Apesar da baixa produção , quando comparada com as outras frutas tropicais, o Brasil se encontra entre os três países mais produtores do mundo (Aparecido et al., 2013), tendo a região Nordeste como a maior produtora nacional $(44,3 \%)$ dentre as regiões brasileiras. Os dois principais produtores nacionais são os Estados de São Paulo (112779 t) e Pernambuco (107 755 t) que detêm juntos mais de $64 \%$ da produção.

A goiaba produzida no Brasil vem sofrendo tendência à industrialização para a transformação em polpas, doces, purês, dentre outros produtos, como foi observado por Souza (2003) no Estado de São Paulo. Estes autores descreveram que, enquanto a produção para a goiaba de mesa cresceu 7 $\%$, a destinada à indústria atingiu $24 \%$ de crescimento, nos anos de 1998 a 2003. A crescente demanda por processamento, principalmente para a exportação de polpa de goiaba, terá como consequência a elevação da produção de coproduto (tabela V), composto principalmente por sementes e casca, que gera uma proporção de 13,3 a 25 $\%$ de coproduto em relação à matéria natural original (Pereira et al., 2009).

Ao avaliarem os valores nutritivos de silagens de capim elefante adicionada com coproduto da goiaba $(0 ; 5 ; 10 ; 15$ e $20 \%)$, Gonçalves et al. (2004) observaram que níveis de $16,56 \%$ de coproduto de goiaba foi suficiente para atingir a MS mínima necessária $(30 \%)$ para um bom processo fermentativo, que os níveis mínimos de proteína $(7 \%)$, para um bom funcionamento ruminal, não foram atingidos, nem mesmo com o maior nível de inclusão $(20 \%)$ e perceberam que a adição de coproduto da goiaba elevou os valores absolutos de FDA, o que pode vir a comprometer a digestibilidade da MS e o valor nutritivo da silagem.

Lousada Junior et al. (2005), afirmam que apesar das limitações do uso da goiaba na alimentação de ruminantes, quando este é avaliado na forma de subprodutos da extração de suco e polpa para ovinos SPRD, observa-se consumos significativos $(1527,4$ g animal ${ }^{-1} \mathrm{dia}^{-1}$ e $\left.4,45 \% \mathrm{PV}\right)$, no entanto,

Tabela $\boldsymbol{V}$. Matéria seca $(M S)$, proteína bruta $(P B)$, lignina (Lig), extrato etéreo (EE), fibra em detergente neutro (FDN), fibra em detergente ácido (FDA) e matéria mineral (MM) do coproduto da goiaba de acordo com alguns autores. (Dry matter (MS), crude protein (PB), lignin (Lig), ether extract (EE), neutral detergent fiber (FDN), acid detergent fiber (FDA) and mineral matter (MM) of the coproduct guava according to some authors).

\begin{tabular}{lccccccc}
\hline & & \multicolumn{7}{c}{ Composição (\% da MS) } \\
Autor & MS & PB & Lig & EE & FDN & FDA & MM \\
\hline Gonçalves et al. (2004) & 88,80 & 7,80 & - & - & 72,60 & 54,80 & - \\
Nunes et al. (2007) & 86,30 & 8,50 & 18,50 & 6,00 & 73,50 & 54,70 & 3,40 \\
Azevedo et al. (2011) & $13,91^{1}$ & 7,09 & 22,10 & 7,68 & - & 59,74 & - \\
\hline
\end{tabular}

${ }^{1}$ Matéria seca obtida pela análise do coproduto in natura. 
apresentaram baixa digestibilidade dos nutrientes, o que se deve aos elevados teores de tanino presentes nas sementes, e apresentaram balanço positivo de energia e nitrogênio.

Os trabalhos com coproduto de goiaba na dieta de ovinos ainda é escassa e seus efeitos na alimentação e no desempenho produtivo precisam ser mais investigados para se determinar as melhores formas e níveis mais recomendados de inclusão desse coproduto da dieta.

\section{Coprodutodo mamão (CARICA PAPAYA)}

O mamoeiro (Carica papaya) é originário da América Central, próximo ao Golfo do México, tendo o Brasil como líder do ranking mundial de produção de mamão, sendo responsável por $25 \%$ da produção mundial (Bezerra et al. 2011). Em 2011, o Brasil alcançou $1854343 \mathrm{t}$, provenientes de uma área colhida de 35531 hectares, tendo a região Nordeste como a líder no ranking nacional, com 1174510 t, que representa mais de $63,3 \%$ de toda a produção (IBGE, 2011). Os três Estados que se destacam como maiores produtores de mamão do Brasil são a Bahia (928 035 t), Espírito Santo (560,576 t) e Ceará (112 579 t), que juntos produziram o equivalente a $86 \%$ do mamão brasileiro.

A comercialização do mamão se dá, principalmente na forma do fruto in natura, o que pressupõe que a maior parte do coproduto produzido por esse segmento é composto de frutos refugados durante o processo de produção e seleção para comercialização. Essas perdas têm sido pouco estudadas, havendo dados quase que inexistentes sobre sua utilização.

Araújo et al. (2010), ao realizarem um levantamento das perdas de produção do mamão no extremo sul da Bahia, concluíram que as maiores perdas $(7,6 \%)$ ocorreram dentro da propriedade, e que esta fato está associado aos frutos que não tiveram desenvolvimento pleno e nem atenderam aos padrões do mercado $(2,87 \%)$, aos frutos maduros que desprendem naturalmente da planta $(1,88 \%)$, ao armazenamento na propriedade $(1,38 \%)$, ao transporte interno $(0,47 \%)$ e ao transporte até o local da venda $(1,0 \%)$.

Diante da magnitude das perdas, que podem chegar até $18,87 \%$ da produção quando se avalia toda a cadeia produtiva, observa-se que só em nível de propriedade a disponibilidade de coprodutos gerados pelo refugo dos frutos no Brasil situou-se ao redor de $140930 \mathrm{t}$, considerando a produção anual de 2011. De certo modo, essas perdas devem variar em função do nível tecnológico do produtor, da forma de conservação dos frutos, da distância e do tipo de transporte utilizado até o centro consumidor, contudo, reflete uma ideia geral sobre as perdas, já que os dados são escassos.

Apesar da grande produção de refugo de mamão, os achados científicos (Lousada Júnior et al., 2005; 2006; Nunes et al., 2007) só se reportam ao potencial de uso dessa fruta sem, no entanto, apresentarem resultados referentes ao seu uso na alimentação de ruminantes. Abrindo, dessa forma, uma lacuna a ser preenchida com estudos com o objetivo de se determinar consumo, nível de inclusão na dieta, digestibilidade, desempenho produtivo, dentre outras respostas importantes à alimentação e nutrição animal.

\section{Coproduto do maracujá (Passiflora EDULIS)}

O maracujá-azedo ou amarelo (Passiflora edulis) é uma fruta tropical nativa e a espécie mais cultivada e comercializada no país, representando mais de $95 \%$ das plantas cultivadas, devido à qualidade de seus frutos (Meletti, 2011). No panorama mundial, o Brasil liderou a produção dessa fruta com 923035 t, colhidos em 61631 ha, em 2011 (IBGE, 2011). A produção nacional é liderada pela região Nordeste, que detém mais de 70 $\%$ (671 $421 \mathrm{t}$,) da produção anual e abriga os dois Estados com a maior produção, sendo 
Tabela VI. Matéria seca (MS), proteína bruta $(P B)$, lignina (Lig), extrato etéreo (EE), fibra em detergente neutro (FDN), fibra em detergente ácido (FDA) e matéria mineral (MM) do coproduto do maracujá de acordo com alguns autores. (Dry matter (MS), crude protein (PB), total carbohydrate (CT), lignin (Lig), ether extract (EE), neutral detergent fiber (FDN), acid detergent fiber (FDA) and mineral matter (MM) of the coproduct passion fruit according to some authors).

\begin{tabular}{lcccccccc}
\hline \multirow{2}{*}{ Autor } & \multicolumn{7}{c}{ Composição (\% da MS) } \\
& MS & PB & CT & Lig & EE & FDN & FDA & MM \\
\hline Cândido et al. (2007) & 83,30 & 12,00 & - & - & 1,00 & 56,60 & 49,00 & - \\
Cruz et al. (2010) & 85,00 & 13,40 & - & - & 2,50 & 59,00 & 49,20 & 9,90 \\
Lousada Júnior et al. (2006) & 83,33 & 12,36 & 76,80 & 9,45 & 1,00 & 56,15 & 48,90 & 9,84 \\
Pereira et al. (2009) & $18,70^{1}$ & 12,60 & 76,80 & 12,70 & 1,00 & 55,30 & 47,20 & 8,30 \\
\hline
\end{tabular}

${ }^{1}$ Matéria seca obtida pela análise do coproduto in natura.

eles a Bahia (410 078 t) e o Ceará (180692 t).

O maracujá pode ser utilizado para o consumo in natura, na forma de sucos, néctar, mousses, sorvetes, dentre outros produtos, contudo, a forma mais comercializada é como suco, gerando um coproduto (tabela VI) composto por cascas $(60 \%$ do peso do fruto) e por sementes ( 6 a $12 \%$ do peso do fruto), como apontam Coelho et al., 2011. Esses resíduos somam juntos de 66 a $72 \%$ do peso da matéria-prima e podem representar uma produção de 636894 t de coprodutos.

O desempenho produtivo de ovinos em sistema de confinamento foi avaliado por Parente et al. (2009), com diferentes dietas, sendo uma delas a base de $19 \%$ de inclusão do resíduo de maracujá. O consumo de matéria seca (MS) foi elevado para todas as dietas, obtendo-se uma média de $1458,10 \mathrm{~g}$ animal $^{-1} \mathrm{dia}^{-1}$, já para o ganho médio diário de peso $(217,20 \mathrm{~g})$ se destacou em relação às demais.

Lousada Junior et al. (2005), ao avaliar subprodutos da extração de suco e polpa de maracujá na alimentação de ovinos SPRD, observaram elevado consumo de MS (1220,9 g animal ${ }^{-1} \mathrm{dia}^{-1} \mathrm{e} 3,5 \% \mathrm{PV}$ ) que, em associação ao teor de proteína do coproduto em questão $(12,4 \%)$, pode ter levado a um consumo elevado de PB (148,4 $\mathrm{g}$ animal $^{-1} \mathrm{dia}^{-1}$ e $0,43 \%$
PV). Ao avaliarem a digestibilidade dos nutrientes, estes mesmo autores, afirma que foi melhorada ( 50 a $60 \%$ ), pelo baixo teor de lignina $(9,5 \%)$ associado ao bom teor de PB $(12,4 \%)$.

O valor nutritivo de silagens de capimelefante enriquecido com diferentes níveis de resíduo desidratado de maracujá foi avaliado por Neiva et al. (2006), onde foram observados consumos de matéria seca (MS) e de proteína bruta (PB) crescentes em função das proporções, com variações que ocorreram de 444,6 a 793,5 g animal ${ }^{-1} \mathrm{dia}^{-1}$ para a MS e 26,6 a 66,7 $\mathrm{g}_{\text {animal }}{ }^{-1} \mathrm{dia}^{-1}$ para a PB. Comportamento semelhante foi obtido para a digestibilidade desses mesmos nutrientes, havendo variações de acréscimo de 42,9 a $53,6 \%$ e 18,3 a $51,3 \%$, para a MS e PB, respectivamente.

Sena (2011), ao avaliar os efeitos da substituição em diferentes níveis do feno de Tifton 85 pela casca de maracujá no desempenho de cordeiros, recomenda que a substituição do feno de Tifton pelo resíduo seja em torno de 30 a $40 \%$, pois este acarreta em redução de digestibilidade da fibra e rendimentos de carcaça.

\section{CONSIDERAÇÕESFINAIS}

O processo de agroindustrialização de frutas no Brasil tem se consolidado, princi- 


\section{BARRETO, LIMA, SOUZA, MOURA, ALENCARE CHAGAS}

palmente pela demanda apresentada pelos mercados consumidores internos e externos e pelo aumento crescente da fruticultura no Brasil e, mais notadamente, na região Nordeste. Essa consolidação e o acesso aos mercados consumidores mais exigentes tendem a determinar a implantação de processos produtivos mais eficientes e com maior uniformidade, o que refletirá na geração de coprodutos com menos variação na sua composição química.

Esse avanço na agroindustrialização é benéfico ao setor pecuário, tendo em vista que a utilização dos coprodutos pelos

\section{BIBLIOGRAFIA}

Aparecido, L.E.O.; Penha, E.T.S. e Souza, P.S. 2013. Avaliações de substratos no enraizamento das estacas de goiabeira em miniestufas de garrafas PET recicladas. Rev Agrogeoambiental, 5: 19-26.

Araújo, A.C.; Silva, L.M.R.; Khan, A.S. e Araújo, L.V. 2010. A cultura do mamão em municípios do extremo sul da Bahia: análise do índice tecnológico da comercialização e do custo social das perdas. Rev Econ NE, 41: 699-714.

Araújo, C.G.F.; Silva, V.N.; Braga, A.P. e Rangel, A.H.N. 2009. Utilização do refugo de melão (Cucumis melo L.) na suplementação de borregos na caatinga. Rev Verde Agroecologia Desenvolv Sustent, 4: 98-102.

Azevedo, J.A.G.; Valadares Filho, S.C.; Pina, D.S.; Detmann, E.; Valadares, R.F.D.; Pereira, L.G.R.; Souza, N.K.P. e Silva, L.F.C. 2011. Consumo, digestibilidade total, produção de proteína microbiana e balanço de nitrogênio em dietas com subprodutos de frutas para ruminantes. Rev Bras Zootecn, 40: 1052-1060.

Ben Salem, H. 2010. Nutritional management to improve sheep and goat performances in semiarid regions. Rev Bras Zootecn, 39 (Suplemento especial): 337-347.

Bezerra, A.S.; Alves, A.S.; Silva, J.A.; Costa, Z.V.B.; Farias, A.A. e Santos J.G.R. 2011. Atributos físicos em frutos de mamoeiro Havaí (Carica papaya L.) submetido à adubação orgânica. Cadernos de Agroecologia, 6: 1-6.

Bueno, G. e Baccarin, J.G. 2012. Participação das animais mitiga os prováveis impactos ambientais, sendo considerada uma via de mão dupla, com ganhos para todos os setores envolvidos. Contudo, essa revisão bibliográfica deteve-se apenas a analisar o cenário nacional de algumas frutas tropicais, cabendo ainda uma reflexão sobre todos os outros coprodutos gerados pelo beneficiamento e processamento de frutas de clima temperado, cuja produção cresce no Brasil a cada ano, incluindo ainda aqueles que são originários do processamento de oleaginosas para produção de biocombustíveis e das indústrias em geral.

principais frutas brasileiras no comércio internacional: 1997 a 1998. Rev Bras Fruticult, 34: 424-434.

Brasil. Ministério do Desenvolvimento, Indústria e Comércio Exterior-MDIC. Secretaria de Comércio Exterior - SECEX. 2013. ALICEWEb2. Brasília, DF. Disponível em: http://aliceweb2.mdic.gov.br (06/06/13).

Candido, M.J.D.; Neiva, J.N.M.; Rodriguez N.M. e Ferreira, C.H. 2007. Características fermentativas e composição química de silagens de capim elefante contendo subproduto desidratado do maracujá. Rev Bras Zootecn, 36 (Suplemento): 1489-1494.

Carvalho, S.; Pires, C.C.; Wommer, T.P.; Pelegrin, A.C.R.S.; Moro, A.B.; Venturini. R.S. e Brutti, D.D. 2012. Características da carcaça de cordeiros alimentados com dietas contendo diferentes resíduos agroindustriais. Rev Agrarian, 5: 409-416.

Coelho, A.A.; Cenci, S.A. e Resende, E.D. 2011. Rendimento em suco e resíduos do maracujá em função do tamanho dos frutos em diferentes pontos de colheita para o armazenamento. Rev Bras Produtos Agroind, 13: 55-63.

Costa. J.M.C.; Felipe, E.M.F.; Maia, G.A.; Brasil, I.M. e Hernandez, F.F.H. 2007. Comparação dos parâmetros físico-químicos e químicos de pós alimentícios obtidos de resíduos de abacaxi. Rev Ciênc Agron, 38: 228-232.

Costa, R.G.; Almeida, C.C.; Pimenta Filho, E.C.; Holanda Júnior, E.V. e Santos, N.M. 2008. 
Caracterização do sistema de produção caprino e ovino na região semiárida do Estado da Paraíba. Brasil. Arch Zootec, 57: 195-205.

Costa, R.G.; Lima, C.A.C.; Medeiros, A.N.; Lima, G.F.C.L.; Marques, C.A.T. e Santos, N.M. 2011a. Característica de carcaça de cordeiros Morada Nova alimentados com diferentes níveis de fruto-refugo de melão em substituição ao milho moído na dieta. Rev Bras Zootecn, 40: 866-871.

Costa, R.G.; Lima, C.A.C.; Medeiros, A.N.; Lima, G.F.C.; Marques, C.A.T. e Queiroga, R.C.R.E. 2011b. Composição centesimal e análise sensorial da carne de ovinos Morada Nova alimentados com dietas contendo melão em substituição ao milho. Rev Bras Zootecn, 40: 27992804.

Cruz, B.C.C.; Santos-Cruz, C.L.; Pires, A.J.V.; Rocha, J.B.; Santos, S. e Bastos, M.P.V. 2010. Composição bromatológica da silagem de capimelefante com diferentes proporções de casca desidratada de maracujá (Passiflora edulis Sims f. flavicarpa). Rev Bras Ciênc Agrár, 5: 434-440.

Dantas Filho, L.A.; Lopes, J.B.; Vasconcelos, V.R.; Oliveira, M.E.; Alves, A.A.; Araújo, D.L.C. e Conceição, W.L.F. 2007. Inclusão de polpa de caju desidratada na alimentação de ovinos: desempenho, digestibilidade e balanço de nitrogênio. Rev Bras Zootec, 36: 147-154.

Ferreira, A.C.H.; Neiva, J.N.M.; Rodriguez, N.M.; Lobo, R.N.B. e Vasconcelos, V.R. 2004. Valor nutritivo das silagens de capim-elefante com diferentes níveis de subprodutos da indústria do suco de caju. Rev Bras Zootec, 33: 13801385.

Ferreira, A.C.H.; Neiva, J.N.M.; Rodriguez, N.M.; Campos, W.E. e Borges, I. 2009. Avaliação nutricional do subproduto da agroindústria de abacaxi como aditivo de ensilagem de capimelefante. Rev Bras Zootec, 38: 223-229.

Ferreira, A.C.H.; Rodriguez, N.M.; Neiva, J.N.M.; Campos, W.E. e Borges, I. 2007. Características químico-bromatológicas e fermentativas do capim-elefante ensilado com níveis crescentes de subprodutos da agroindústria do abacaxi. Rev Ceres, 54: 98-106.

François, P. 2009. Desempenho, características de carcaça e a utilização da carne de ovelhas de descarte terminadas em pastagem cultivada na elaboração de embutido fermentado. Tese de mestrado. Universidade Federal de Santa Maria. Santa Maria/Rio Grande do Sul. 85 pp.

Geron, L.J.V.; Mexia, A.A.; Garcia, J.; Silva, M.M. e Zeoula, L.M. 2012. Suplementação concentrada para cordeiros terminados a pasto sobre o custo de produção no período de seca. Semin: Ciênc Agrár, 33: 797-808.

Gonçalves, J.S.; Neiva, J.N.M.; Vieira, N.M.; Oliveira Filho, G.S. e Lobo, R.N.B. 2004. Valor nutritivo de silagem de capim elefante (Pennissetum purpureum Schum.) com adição de diferentes níveis de subprodutos do processamento de acerola (Malpighia glabra L.) e de goiaba (Psidium guajava L.). Rev Ciênc Agron, 35: 131-137.

IBGE - Instituto Brasileiro de Geografia e Estatística. 2011. Produção Agrícola Municipal: culturas temporárias e permanentes. Rio de Janeiro. IBGE, 38: $97 \mathrm{pp}$.

IBGE - Instituto Brasileiro de Geografia e Estatística. 2013a. Sistema IBGE de Recuperação Automática. Disponível em http://www.sidra.lbge. gov.br (01/05/13).

IBGE - Instituto Brasileiro de Geografia e Estatística. 2013b. Levantamento Sistemático da Produção Agrícola: pesquisa mensal de previsão e acompanhamento das safras agrícolas no ano civil. Rio de Janeiro. IBGE, 26: 1-86.

Jerônimo, C.E.M. 2012. Gestão agroindustrial: pontos críticos de controle ambiental no beneficiamento de frutas. Rev Adm Roraima, 12: 70-77.

Kist, B.B.; Vencato, A.Z.; Santos, C.; Carvalho, C.; Reetz, E.R.; Poll, H. e Beling, R.R. 2012. Anuário brasileiro da fruticultura 2012. Gazeta Santa Cruz. Santa Cruz do Sul. 128 pp.

Lima, C.A.C.; Lima, G.F.C.; Costa, R.G.; Medeiros, A.N.; Aguiar, E.M. e Lima Júnior, V. 2012. Efeito de níveis de melão em substituição ao milho moído sobre o desempenho, o consumo e a digestibilidade dos nutrientes em ovinos Morada Nova. Rev Bras Zootecn, 41: 164-171.

Lima, G.F.C.; Silva, J.G.M.; Aguiar, E.M.; Ferreira, M.A.; Rangel, A.H.N. e Torres, J.F. 2011. Frutosrefugo de melão em substituição ao farelo de trigo na alimentação de vacas leiteiras. Rev Caatinga, 24: 190-197.

Lopes, M.M.A.; Moura, C.F.H.; Aragão, F.A.S.; Cardoso, T.G. e Enéas Filho, J. 2011. Caracterização física de pedúnculo de clones de cajueiro anão precoce em diferentes estádios de 


\section{BARRETO, LIMA, SOUZA, MOURA, ALENCARE CHAGAS}

maturação. Rev Ciênc Agron, 42: 914-920.

Lousada Júnior, J.E.; Costa, J.M.C.; Neiva, J.N.M. e Rodriguez, N.M. 2006. Caracterização físicoquímica de subprodutos obtidos do processamento de frutas tropicais visando o seu aproveitamento na alimentação animal. Rev Ciênc Agron, 37: 70-76.

Lousada Júnior, J.E.; Neiva, J.M.N.; Rodriguez, N.M.; Pimentel, J.C.M. e Lobo, R.N.B. 2005. Consumo e digestibilidade de subprodutos do processamento de frutas em ovinos. Rev Bras Zootecn, 34: 659-669.

Machado, A.V.; Oliveira, E.L.; Oliveira, J.A.; Souza, D.F.S. e Freitas, L.M. 2012. Modelagem e simulação da secagem solar do pedúnculo de caju. Rev Verde Agroecologia Desenvolv Sustent, 7: 94-101.

Meletti, L.M.M. 2011. Avanços na cultura do maracujá no Brasil. Rev Bras Fruticult, (Volume Especial): 83-91.

Naumov, A. 2009. Fruteiras tropicais. In: L.A. Crisóstomo e A. Naumov (Eds.). Adubando para alta produtividade e qualidade: fruteiras tropicais do Brasil. Tradução de L. Araújo Crisóstomo. Embrapa Agroindústria Tropical. Fortaleza/CE. pp. 6-12.

Neiva, J.N.M.; Nunes, F.C.S.; Cândido, M.J.D.; Rodriguez, N.M. e Lobo, R.N.B. 2006. Valor nutritivo de silagens de capim-elefante enriquecidas com resíduo do processamento do maracujá. Rev Bras Zootecn, 35 (Suplemento): 1843-1849.

Neiva, J.N.M.; Ferreira, A.C.H.; Rodriguez, N.M.; Santana, G.Z.M.; Borges, I. e Lobo, R.N.B. 2009. Desempenho produtivo de ovinos alimentados com silagens de capim-elefante contendo subprodutos de processamento de frutas. Rev Ciênc Agron, 40: 315-322.

Nogueira, N.W.; Freitas, R.M.O.; Sarmento, J.D.A.; Leal, C.C.P. e Castro, M.P. 2010. Alternativas alimentares para ovinos e caprinos no semiárido brasileiro. Rev Verde Agroecologia Desenvolv Sustent, 5: 05-12.

Nunes, H.; Zanine, A.M.; Machado, T.M.M. e Carvalho, F.C. 2007. Alimentos alternativos na dieta de ovinos: Uma revisão. Arch Latinoam Prod Anim, 15: 147-158.

Parente, H.N.; Machado, T.M.M.; Carvalho, F.C.; Garcia, R.; Rogério, M.C.P.; Barros, N.N.N. e Zanine, A.M. 2009. Desempenho produtivo de ovinos em confinamento alimentados com diferentes dietas. Arq BrasMed Vet Zoo, 61: 460466.

Pereira, E.S.; Pimentel, P.G.; Duarte, L.S. Villarroel, A.B.S.; Regadas Filho, J.G.L. e Rocha Júnior, J.N. 2010. Digestão intestinal da proteína de forrageiras e coprodutos da agroindústria produzidos no Nordeste brasileiro por intermédio de três estágios. Rev Bras Saúde Prod Anim, 11: 403-413.

Pereira, L.G.R.; Azevedo, J.A.G.; Pina, D.S.; Brandão, L.G.N.; Araújo, G.G.L. e Volyolini, T.V. 2009. Aproveitamento dos coprodutos da agroindústria processadora de suco e de polpa de frutas na alimentação de ruminantes. Embrapa Semiárido, Petrolina. (Embrapa Semiárido. Documentos, 220). 30 pp.

Pompeu, R.C.F.F; Neiva, J.N.M.; Cândido, M.J.D.; Oliveira Filho, G.S.; Aquino, D.C. e Lobo, R.N.B. 2006. Valor nutritivo de silagens de capimelefante (Pennisetum purpureum Schum.) com adição de subprodutos do processamento de frutas tropicais. Rev Ciênc Agron, 37: 77-83.

Rogério, M.C.P.; Borges, I.; Neiva, J.N.M.; Rodriguez, N.M.; Pimentel, J.C.M.; Martins, G.A.; Ribeiro, T.P.; Costa, J.B.; Santos, A.F. e Carvalho, F.C. 2007. Valor nutritivo do resíduo da indústria processadora de abacaxi (Ananas comosus L.) em dietas para ovinos. 1. Consumo, digestibilidade aparente e balanços energético e nitrogenado. Arq Bras Med Vet Zootec, 59: 773-781.

Sá, C.O.; Sá, J.L.; Muniz, E.N. e Costa, C.X. 2008. Aspectos técnicos e econômicos da terminação de cordeiros a pasto e em confinamento. Tecnol Ciên Agropec, 2: 47-55.

Santana, G.Z.M.; Neiva, J.N.M.; Oliveira, A.L.; Borges, I.; Moraes, S.A.; Freire, A.C.H.; Aquinos, D.C.e Sá, C.R.L. 2004. Rendimentos de carcaça e de cortes cárneos de cordeiros Santa Inês alimentados com dietas contendo subprodutos agroindustriais. Anais da XLI Reunião Anual da Sociedade Brasileira de Zootecnia. Campo Grande/MS. Brasil. 5 pp.

Schneider, V.E.; Peresin, D.; Trentin, A.C.; Bortolin, T.A. e Sambuichi, R.H.R. 2012. Diagnóstico dos resíduos orgânicos do setor agrossilvopastoril e agroindústrias associadas. Instituto de Pesquisa Econômica Aplicada (IPEA). Brasília. 134 pp. Sena, J.A.B. 2011. Consumo, digestibilidade e 


\section{USO DE COPRODUTOS DE FRUTAS TROPICAIS NA ALIMENTAÇÃO DE OVINOS}

desempenho de ovinos alimentados com casca de maracujá desidratada. Tese de mestrado. Universidade Federal dos Vales do Jequitinhonha e Mucuri, Diamantina. Diamantina/Minas Gerais. 57 pp.

Silva, L.M. Oliveira; C.H.A, Rodrigues, F.V.; Rodrigues, M.R.C.; Beserra, F.J.; Silva, A.M.; Lemos, J.C.; Fernandes, A.A.O. e Rondina, D. 2011. Desempenho e características da carcaça de cordeiros alimentados com bagaço de caju. Arch Zootec, 60: 777-786.

Silva, N.V.; Costa, R.G.; Freitas, C.R.G.; Galindo, M.C.T.e Silva, L.S. 2010. Alimentação de ovinos em regiões semiáridas do Brasil. Acta Vet Bras, 4: 233-241.

Sousa, B.A.A. and Correia, R.T.P. 2010. Biotechnological reuse of fruit residues as a rational strategy for agro-industrial resources. $J$ Tech Manage Innov, 5: 104-112.

Souza, A.C.G. 2003. Industrialização da polpa e suco de goiaba. In: Rozane, D.E. e Couto, F.A.d'A.
(Eds.). Cultura da goiabeira: tecnologia e mercado. Universidade Federal de Viçosa. Viçosa/ Minas Gerais. pp. 1-10.

Souza Filho, H.M.; Guanziroli, C.E.; Figueiredo, A.M. e Valente Júnior, A.S. 2010. Barreiras às novas formas de coordenação no agrossistema do caju na região nordeste, Brasil. Gest Prod, 17: 229-244.

Teixeira, M.C.; Neiva, J.N.M. e Moraes, S, A. 2003. Desempenho de ovinos alimentados com dietas à base de silagem de capim elefante (Pennisetum purpureum, Schum) contendo ou não bagaço de caju (Annacardium occidentale, L.). Anais da XL Reunião Anual da Sociedade Brasileira de Zootecnia. Santa Maria/RS. Brasil. 5 pp.

Teles, M.M.; Neiva, J.N.M.; Clementino, R.H.; Rego, A.C.; Candido, M.J.D. e Restle, J. 2010. Consumo, digestibilidade de nutrientes e balanço de nitrogênio da silagem de capim-elefante com adição de pedúnculo de caju desidratado. Ciênc Rural, 40: 427-433. 